\title{
Comparison of Surgery with Radiotherapy and Androgen Deprivation Treatment Combination in the Management of High-risk Prostate Cancer
}

\author{
Murat Öztürk ${ }^{1}, \oplus$ Gül Ayşen Öztürk ${ }^{2}, \odot$ Nizameddin Koca $^{3}, \oplus$ Abdullah Güll ${ }^{1}, \odot$ Yavuz Baştuğ ${ }^{4}$, \\ Serdar Aykan ${ }^{4}$ \\ ${ }^{1}$ Department of Urology, University of Health Sciences, Bursa Yuksek Ihtisas Training and Research Hospital, Bursa, Turkey \\ ${ }^{2}$ Department of Radiation Oncology, Bursa City Hospital, Bursa, Turkey \\ ${ }^{3}$ Department of Internal Medicine, University of Health Sciences, Bursa Yuksek Ihtisas Training and Research Hospital, Bursa, Turkey \\ ${ }^{4}$ Department of Urology, University of Health Sciences Turkey, Haydarpasa Numune Health Application and Research Center, Istanbul, Turkey
}

\begin{abstract}
Introduction: We aimed to compare the outcomes of high risk prostate cancer treatments with radical prostatectomy (RP) or radiotherapy (RT) and androgen deprivation therapy (ADT).

Methods: 83 patients who were treated with RT and ADT or radical prostatectomy for high risk prostate cancer between April 2010 and May 2018 and whose data were retrospectively analyzed were included in our study. While 40 patients received RT and ADT combination therapy, 43 patients received RP. The groups were compared in terms of pre-treatment general features, post-treatment biochemical recurrence, metastasis, disease-free survival and overall survival.

Results: The mean age of the patients was 64.05 (50-74) years in the surgical group and 69.35 (49-79) years in the RT group. The mean prostate-specific antigen baseline value was 22.79 (3-93) ng/ml in the surgical group and 40.60 (3-201) ng/ml in the RT group. Biochemical recurrence was observed in 15 (34.8\%) patients in the surgical group and 2 (5\%) patients in the RT group. Disease-free survival time was 31.12 (12-68) months in the surgical group and 41.4 (16-88) months in the RT group. Discussion and Conclusion: Our study results revealed that RT and ADT application has more advantageous oncological results in the treatment of high-risk prostate cancer, as in many studies.

Keywords: Androgen deprivation therapy (ADT); prostate cancer; radical prostatectomy; radiotherapy.
\end{abstract}

W hile prostate cancer is the most common cancer in men worlwide, in Turkey it only takes second place after lung cancer ${ }^{[1]}$. It is the most commonly diagnosed solid organ tumor among men in America. It is reported that in 2018, 164.690 new cases developed in America and 29.430 people died due to prostate cancer ${ }^{[2]}$. In the pres- ence of prostate cancer in first degree relatives, the risk is doubled. If it is seen in two or more first-degree relatives, this risk increases 5-11 times ${ }^{[3,4]}$.

With the widespread use of the prostate-specific antigen (PSA) test, rates of diagnosing prostate cancer have increased significantly. Patients diagnosed with prostate 
cancer are divided into low, medium and high risk groups according to Gleason score (GS), PSA level and T stage. According to the D'Amico risk group classification, high-risk prostate cancer should have a PSA value $>20 \mathrm{ng} / \mathrm{mL}$ at the time of diagnosis or GS $>7$ or clinical T stage $\geq 3 a^{[5,6]}$. Approximately $40 \%$ of cases at the time of diagnosis are high-risk prostate cancer. These cases may show progression and go up to death ${ }^{[7]}$.

When making a treatment decision in a patient diagnosed with prostate cancer, many factors such as the patient's stage, risk group, patient's age, expected life span, and performance status should be considered. If the tumor is limited in the prostate tissue, radical prostatectomy is generally recommended, while curative radiotherapy (RT) is recommended in the presence of extracapsular disease, seminal vesicle invasion, lymph node positivity during diagnosis, and patients classified in the high-risk group ${ }^{[8]}$. In addition to patients undergoing curative RT as a primary treatment, androgen deprivation therapy (ADT) is applied for 2-3 years ${ }^{[9,10]}$. In metastatic prostate cancer, chemotherapy and ADT treatment come to the agenda ${ }^{[11]}$.

While men with high-risk disease commonly are treated by RT and ADT, there are also instances when RP is beneficial $^{[10,12]}$.

In our study, we aimed to compare the results of RP with curative RT and ADT in the treatment of high-risk prostate cancer.

\section{Materials and Methods}

In our research, we studied with 83 patients who were treated with RT and ADT or radical prostatectomy for at least 12 months due to high-risk prostate cancer between April 2010 and May 2018, and retrospectively analyzed data were included. The protocol was approved by the Bursa Yüksek Ihtisas Education and Research Hospital Ethics Committee (2011-KAEK-25 2019/02-03). While 40 patients received RT and ADT combination therapy, 43 patients received RP. Patients who did not have metastasis at the time of diagnosis, followed up for at least 3 months after treatment participated in the study.

Intensity-modulated RT (IMRT) technique was used in all patients receiving RT with the Tomotherapy Hi-Art device. Prostate, seminal vesicle and pelvic lymph nodes were included in the RT area. The patients were treated with bladder-filled and rectum empty. Prostata was applied with 74 $\mathrm{Gy}$ in 33 fractions, $60 \mathrm{~Gy}$ for seminal vesicles and $52 \mathrm{~Gy}$ for pelvic lymph nodes. Curative doses are provided in target tissues by adjusting dose densities with the IMRT tech- nique, while maximum protection is provided in neighboring organs (bladder, rectum and femoral heads). ADT is starting 2 months before the treatment for all patients receiving RT and was applied for 2-3 years. In the post-treatment follow-up, the increase of the PSA rare level above $2 \mathrm{ng} / \mathrm{ml}$ was considered as recurrence.

Open radical prostatectomy and bilateral lymph node dissection were performed to all patients in the surgical group. Patients who received RT or ADT before surgery were excluded from the study. Patients with a PSA level above 0.2 $\mathrm{ng} / \mathrm{ml}$ in the postoperative period were considered as biochemical recurrences.

After the treatment, the cases were followed up with a total PSA every 2 months and 3 months, then every 6 months and tomography scan once a year.

\section{Statistical Analysis}

SPSS 20.0 statistical analysis (SPSS Inc. Chicago, IL, USA) software package program was used in our study to evaluate the results. Descriptive statistics of all variables in the study were calculated. The normality of the distribution of the data was evaluated by the Shapiro-wilk test, and its homogeneity by the Levene test. Continuous variables were given as mean \pm standard deviation. For comparison of numerical data between groups, Kruskal-wallis test was used for non-parametric data and student-t test was used for parametric data. In case of significance, binary comparisons were made with the Mann-Whitney $U$ test. Categorical variables were compared with chi-square test, Pearson chi-square and Fisher's exact chi-square test. Survival analysis was performed using tiger-meier survival analysis. $\mathrm{P}<0.05$ was considered to be statistically significant.

\section{Results}

Demographic features, clinical and pathological findings of the cases were compared as surgical and RT groups. Average age was $69.35 \pm 7.00$ (49-79) in patients undergoing RT, 64.05 \pm 5.93 (50-74) in patients undergoing surgery, and average baseline PSA values in the RT group was found to be $40.60 \pm 42.87(3-201) \mathrm{ng} / \mathrm{ml}$, and $22.73 \pm 21.01$ in the surgical group 3-93) $\mathrm{ng} / \mathrm{mL}$. The mean follow-up time was 41.6 months in the surgical group and 44.37 months in the RT group. When both groups were compared in terms of clinical stage, it was seen that RT group was in an advanced stage (Table 1).

Comparing the biopsy and prostatectomy pathologies of the surgical group, upgrading was detected in 24 (55.81\%) of the patients, while no downstaging was detected in any 
Table 1. Comparison of descriptive statistics of groups

\begin{tabular}{|c|c|c|c|c|c|}
\hline & \multicolumn{2}{|c|}{ Surgery $(n=43)$} & \multicolumn{2}{|c|}{ Radiotherapy $(n=40)$} & \multirow[t]{2}{*}{$\mathbf{p}$} \\
\hline & Mean \pm SD & Minimum/Maximum & Mean \pm SD & Minimum/Maximum & \\
\hline Age of diagnosis & $64.05 \pm 5.93$ & $50-74$ & $69.35 \pm 7.00$ & $49-79$ & 0.000 \\
\hline PSA & $22.73 \pm 21.01$ & $3-93$ & $40.60 \pm 42.87$ & $3-201$ & 0.007 \\
\hline Number of positive cores & $6.33 \pm 1.22$ & $4-9$ & $6: 18 \pm 1.10$ & $4-8$ & 0.791 \\
\hline Diagnostic Gleason Score & $7.65 \pm 0.78$ & $6-9$ & $7: 38 \pm 1.27$ & 4-10 & 0.234 \\
\hline Clinical Stage & & & & & 0.000 \\
\hline T1c & 19 & & - & & \\
\hline $\mathrm{T} 2$ & 9 & & - & & \\
\hline $\mathrm{t} 2 \mathrm{~B}$ & 4 & & 7 & & \\
\hline $\mathrm{T} 2 \mathrm{C}$ & 4 & & 26 & & \\
\hline T3 & 7 & & 7 & & \\
\hline Recurrence, n (\%) & $15(34.8)$ & & $2(5)$ & & 0.001 \\
\hline Bone met, n (\%) & $11(25.58)$ & & $1(2.5)$ & & 0.003 \\
\hline DFS & $31.12 \pm 20.91$ & $12-68$ & $41.40 \pm 19.29$ & $16-88$ & 0.036 \\
\hline Excitus, n (\%) & $3.9(6.9)$ & & $1(2.5)$ & 0.218 & \\
\hline OS & $42.28 \pm 18.76$ & $14(70)$ & $46.15 \pm 20.75$ & $19-96$ & 0.827 \\
\hline
\end{tabular}

SD: Standard deviation; PSA: Prostate-specific antigen.

patient. Gleason pattern 5 was observed in the prostatectomy pathologies of 19 patients and BKN was observed in 10 (52.63\%) of these patients. In RT group BKN was observed in 1 of 7 patients with Gleason pattern 5.

In the surgical group, the average number of positive cores in 12 core biopsies was $6.33 \pm 1.22$ (4-9), while it was 4.07 in those without BKN and 7.6 in those without BKN. In RT group, the average positive core number of 12 core biopsies was $6.18 \pm 1.10(4-8)$, whereas in the cases without BKN, 6.1 positive and in two cases with BKN, an average of 7.5 positive cores were detected. In the surgical group, 13 patients had SVI, 13 patients had ESR, 11 patients had CS positivity, and 6 patients had post op lymph node positivity.

All RT patients were treated with IMRT technique. Adjacent organ doses (bladder, rectum, femoral heads and small intestine) were kept within safe dose limits according to the QUANTEC criteria. PSA recurrence developed in one patient at 24 months and in another 52 months at RT and ADT, and bone metastasis developed at 60 months. These patients received $\mathrm{CT}$ and palliative $\mathrm{RT}$ for bone metastasis. In another patient, the second primary bladder was detected in the $7^{\text {th }}$ year. In this patient, transurethral resection was applied to the mass in the bladder.

Recurrence of PSA was observed in 15 (34.8\%) patients after surgery. $9(20.9 \%)$ patients of them received MAB and 6 (13.9\%) patients received salvage RT. Chemotherapy was applied to one patient who relapsed after salvage RT. Bone metastasis developed in 11 (25.5\%) patients in this group. When the disease-free survival was examined, the average of the surgery group was $31.12 \pm 20.91$ (12-68) months, while it was $41.40 \pm 19.29$ (16-88) months in the group receiving RT and ADT. This result was found statistically significant in favor of RT group $(p=0.036)$.

\section{Discussion}

Radical prostatectomy or RT is applied as the primary treatment in patients in low and medium risk groups who are thought to be local with a life expectancy of 10 years or more ${ }^{[13]}$. In high-risk prostate cancer, treatment methods are not yet clear. Despite many different definitions, the most commonly accepted definition is the classification of $D^{\prime}$ amico ${ }^{[14]}$. Today, there are studies in which surgery is recommended to patients in this group as an alternative to RT and hormonotherapy combination ${ }^{[15,16]}$.

In high-risk prostate cancer, worse results are reported in terms of recurrence, disease-free survival period and survival periods compared to low and medium-risk patients. In the studies conducted, it is observed that patients with positive positivity for SVI, EKY, and CS after RP were better treated with early RT after surgery instead of RP alone ${ }^{[17,18]}$. In fact, there are studies reporting that postoperative PSA recurrence has better results in early salvage $\mathrm{RT}^{[19]}$. In our study, SVI in 13 patients, EKY in 13 patients, CS positivity in 11 patients and post op lymph node positivity in 6 pa- 
tients were detected. In the surgical group, 6 patients had adjuvant RT in the early post-op period, and 6 patients was applied with salvage RT.

In conducted studies, PSA $>20 \mathrm{ng} / \mathrm{mL}$ and in patients with prostate $\mathrm{Ca}$, which is considered to be clinically limited to the organ, PSA failure rate at 5 years after RP monotherapy is $44-50 \%$, the cancer specific survival rates at 10 and 15 years after RP was reported as $90 \%$ and $85 \%{ }^{[20-22]}$.

In the present study, the rate of BKN was $34.09 \%$ in the surgical group and $5 \%$ in the group receiving RT and ADT. This rate was found to be $42.3 \%$ in the surgical group and $7.2 \%$ in the RT and ADT study in the study of Baker et al. ${ }^{[23]}$. In that study, patients with elevated PSA after salvage RT were accepted as BKN. In the study conducted by Watkins et al., ${ }^{[24]}$ the 5 -year BKN rate was found to be $79.4 \%$ in the surgical group and $25.2 \%$ in the RT group. However, in this study, patients who received salvage RT due to the development of BKN accepted biochemical failure. In the study that was carried out by Yıkılmaz et al. in Turkey, $55 \%$ of the patients who underwent surgery due to high-risk prostate cancer had BKN, while this rate was found to be $10 \%$ in the group receiving $\mathrm{RT}^{[25]}$. In this study, the disease-free survival period was 18.1 (10-31) months in the surgical group and 45.1 (6-104) months in the RT group. In our study, disease-free survival in the surgical group was 31.1 (3-68) months while it was 41.4 (16-88) months in RT group.

One of the difficulties of comparing treatment methods in the high-risk disease group is the heterogeneity in biological behavior and clinical course being not sufficiently known. Only the treatment results of high-risk patients have different potential to respond to systemic neoadjuvant therapies according to the biological features of the tumor ${ }^{[26]}$.

There are studies showing that RT dose is effective in biochemical recurrence in patients undergoing RT. The dose given at $72 \mathrm{~Gy}$ and above in medium and high-risk patients has been shown to provide better biochemical recurrencefree survival than the dose administered below $72 \mathrm{~Gy}^{[27]}$. In the study conducted by Yıkılmaz et al., it was reported that $22 \%$ of patients who underwent $3 \mathrm{D}$ conformal RT under 72 Gy in the RT and ADT group were observed in $22 \%$ of the patients, while $4 \%$ of the patients who received 72 Gy and above IMRT were observed ${ }^{[25]}$. In our study, all patients had IMRT above 72 Gy and our rate of BKN was $5 \%$.

\section{Conclusion}

In parallel with previous studies, we found that patients who received $R T$ and ADT in patients with high-risk prostate cancer were more advantageous in terms of biochemical recurrence, development of metastases and disease-free lifetimes compared to previous studies. We have seen that surgery alone is not sufficient in this group of patients and there is a high need for postoperative adjuvant therapy. Therefore, we think that it will be appropriate to make the treatment decisions to be applied to the patients after the disease is determined by looking at the patient criteria with a multidisciplinary approach. Therefore, we think that it would be appropriate to make the treatment decisions for the patients with a multidisciplinary approach, only after the disease is fully determined in the light of patient specific test results and classification.

Ethical Committee Approval: The protocol was approved by the Bursa Yüksek Ihtisas Education and Research Hospital Ethics Committee (2011-KAEK-25 2019/02-03).

Peer-review: Externally peer-reviewed.

Authorship Contributions: Concept: M.Ö., G.A.Ö., S.A.; Design: A.G., Y.B.; Data Collection or Processing: M.Ö., S.A., G.A.Ö.; Analysis or Interpretation: N.K., Y.B.; Literature Search: S.A., G.A., Ö.A.G.; Writing: M.Ö.

Conflict of Interest: None declared.

Financial Disclosure: The authors declared that this study received no financial support.

\section{References}

1. Günay LM, Tombul ŞT, Akdoğan B. Lokalize prostat kanseri küratif tedavi seçenekleri sonrası yükselen PSA'ya algoritmik yaklaşım. Üroonkol Derneği Yönetim Kurulu 2011;51:5-138.

2. Cancer Facts and Figures; 2018. Available at: https://www. cancer.org/content/dam/cancer-org/research/cancer-factsandstatistics/annual-cancer-facts-and-figures/2018/cancerfacts-and-figures-2018.pdf. Accessed Mar 15,2018.

3. Leitzmann MF, Rohrmann S. Risk factors for the onset of prostatic cancer: Age, location, and behavioral correlates. Clin Epidemiol 2012;4:1. [CrossRef]

4. Esposito K, Chiodini P, Capuano A, Bellastella G, Maiorino MI, Parretta $E$, et al. Effect of metabolic syndrome and its components on prostate cancer risk: Meta-analysis. J Endocrinol Invest 2013;36:132-9. [CrossRef]

5. Boorjian SA, Karnes RJ, Rangel LJ, Bergstralh EJ, Blute ML. Mayo clinic validation of the D'amico risk group classification for predicting survival following radical prostatectomy. J Urol 2008;179:1354-61. [CrossRef]

6. Heidenreich A, Bastian PJ, Bellmunt J, Bolla M, Joniau S, van der Kwast $\mathrm{T}$, et al. EAU guidelines on prostate cancer. Part 1: Screening, diagnosis, and local treatment with curative intent-update 2013. Eur Urol 2014;65:124-37. [CrossRef]

7. Yossepowitch O, Eggener SE, Serio AM, Carver BS, Bianco FJ Jr., Scardino PT, et al. Secondary therapy, metastatic progression, 
and cancer-specific mortality in men with clinically high-risk prostate cancer treated with radical prostatectomy. Eur Urol 2008;53:950-9. [CrossRef]

8. Gürer E, Turna B. Lokalize prostat kanseri: Tedavi seçenekleri. Turk Klinikleri Urol Spec Top 2012;5:56-65.

9. Horwitz EM, Bae K, Hanks GE, Porter A, Grignon DJ, Brereton $H D$, et al. Ten-year follow-up of radiation therapy oncology group protocol 92-02: A Phase III trial of the duration of elective androgen deprivation in locally advanced prostate cancer. J Clin Oncol 2008;26:2497-504. [CrossRef]

10. Bolla M, Van Tienhoven $G$, Warde $P$, Dubois JB, Mirimanoff $\mathrm{RO}$, Storme G, et al. External irradiation with or without longterm androgen suppression for prostate cancer with high metastatic risk: 10-year results of an EORTC randomised study. Lancet Oncol 2010;11:1066-73. [CrossRef]

11. Andriole GL, Crawford ED, Grubb RL, Buys SS, Chia D, Church TR, et al. Mortality results from a randomized prostate-cancer screening trial. N Engl J Med 2009;360:1310-9. [CrossRef]

12. Sundi D, Tosoian JJ, Nyame YA, Alam R, Achim M, Reichard CA, et al. Outcomes of very high-risk prostate cancer after radical prostatectomy: Validation study from 3 centers. Cancer 2019;125:391-7. [CrossRef]

13. Mohler J, Antonorakis E, Armstrong A. NCCN Clinical Practice Guideline in Oncology. Prostate Cancer. United States: National Comprehensive Cancer Network; 2017.

14. D'Amico AV, Whittington R, Malkowicz SB, Schultz D, Blank K, Broderick GA, et al. Biochemical outcome after radical prostatectomy, external beam radiation therapy, or interstitial radiation therapy for clinically localized prostate cancer. JAMA 1998;280:969-74. [CrossRef]

15. Bolla M, Collette L, Blank L, Warde P, Dubois JB, Mirimanoff RO, et al. Long-term results with immediate androgen suppression and external irradiation in patients with locally advanced prostate cancer (an EORTC study): A Phase III randomised trial. Lancet 2002;360:103-8. [CrossRef]

16. Van Poppel $H$, Joniau S. An analysis of radical prostatectomy in advanced stage and high-grade prostate cancer. Eur Urol 2008;53:253-9. [CrossRef]

17. Thompson IM, Tangen CM, Paradelo J, Lucia MS, Miller G, Troyer D, et al. Adjuvant radiotherapy for pathological T3NOMO prostate cancer significantly reduces risk of metastases and improves survival: Long-term follow up of a randomized clinical trial. J Urol 2009;181:956-62. [CrossRef]
18. Bolla M, van Poppel H, Collette L, van Cangh P, Vekemans K, Da Pozzo $L$, et al. Postoperative radiotherapy after radical prostatectomy: A randomised controlled trial (EORTC trial 22911). Lancet 2005;366:572-8. [CrossRef]

19. Fossati N, Karnes RJ, Cozzarini C, Fiorino C, Gandaglia G, Joniau $S$, et al. Assessing the optimal timing for early salvage radiation therapy in patients with prostate-specific antigen rise after radical prostatectomy. Eur Urol 2016;69:728-33. [CrossRef]

20. Yossepowitch O, Eggener SE, Bianco FJ, Carver BS, Serio A, Scardino PT, et al. Radical prostatectomy for clinically localized, high risk prostate cancer: Critical analysis of risk assessment methods. J Urol 2007;178:493-9. [CrossRef]

21. D'Amico AV, Whittington R, Malkowicz SB, Fondurulia J, Chen $\mathrm{MH}$, Kaplan I, et al. Pretreatment nomogram for prostate-specific antigen recurrence after radical prostatectomy or external-beam radiation therapy for clinically localized prostate cancer. J Clin Oncol 1999;17:168-72. [CrossRef]

22. Spahn M, Joniau S, Gontero P, Fieuws S, Marchioro G, Tombal $\mathrm{B}$, et al. Outcome predictors of radical prostatectomy in patients with prostate-specific antigen greater than $20 \mathrm{ng} / \mathrm{ml}$ : A European multi-institutional study of 712 patients. Eur Urol 2010;58:1-7. [CrossRef]

23. Baker CB, McDonald AM, Yang ES, Jacob R, Rais-Bahrami S, Nix JW, et al. Pelvic radiotherapy versus radical prostatectomy with limited lymph node sampling for high-grade prostate adenocarcinoma. Prost Cancer 2016;2016:2674954.

24. Watkins JM, Watkins PL, Dufan TA, Koleilat N. High-grade prostate adenocarcinoma (Gleason Score $\geq 8$ ): Survival and disease control following radical prostatectomy versus radiotherapy plus long-course hormone therapy. J Radiat Oncol 2015;4:277-82. [CrossRef]

25. Yıkılmaz TN, Öztürk E, Selvi İ, Başar H. Yüksek riskli prostat kanserinde cerrahi ve radyoterapinin onkolojik sonuçlara etkisi. Acta Oncol Turc 2015;50:17-23. [CrossRef]

26. Linch M, Goh G, Hiley C, Shanmugabavan Y, McGranahan N, Rowan $A$, et al. Intratumoural evolutionary landscape of highrisk prostate cancer: The progeny study of genomic and immune parameters. Ann Oncol 2017;28:2472-80. [CrossRef]

27. Kupelian PA, Elshaikh M, Reddy CA, Zippe C, Klein EA. Comparison of the efficacy of local therapies for localized prostate cancer in the prostate-specific antigen era: A large single-institution experience with radical prostatectomy and externalbeam radiotherapy. J Clin Oncol 2002;20:3376-85. [CrossRef] 